\author{
G.S. Rakhymbay*, R.J. Jumanova, B.D. Burkitbayeva, A.M. Argimbaeva, \\ A.P. Kurbatov, M.K. Nauryzbayev \\ Department of Chemistry and Chemical Technology, \\ Al-Farabi Kazakh National University, Almaty, Kazakhstan \\ "E-mail: gulmirarahymbay@gmail.com

\section{Optimization of conditions for electrochemical refining rough indium from chloride electrolytes}

\begin{abstract}
The studies found that the discharge - ionization of indium chloride electrolytes at a platinum electrode have a stepwise character. Analysis of the cyclic voltammetric curves indicates the irreversibility of occurring electrode reactions. Chronoamperometry methods using X-ray diffraction analysis of the electrode surface found the optimal conditions for deposition of indium in chloride electrolytes. Study of the influence of salt concentration of indium in the electrolyte and temperature on the discharge ionization processes indium allowed to establish acceptable values for these parameters

Keywords: indium, polarization, refining, potential, discharge-ionization.
\end{abstract}

\section{Introduction}

The development of new branches of science, technology and industry is impossible without progress in the field of electronics, the level and rate of development of which are largely determined by developments in the field of production of materials of high-purity synthesized from the original metals and metalloids of high-purity. These metals include high-purity indium, which has a number of specific properties [1], allowing to use it extensively in the semiconductor industry [2]. Due to the fact that the most promising methods of refining of indium are electrochemical methods [3], a detailed study of the electrochemical processes at the interface of metalelectrolyte phases makes it possible to find the optimal conditions for purification of rough indium.

A considerable amount of publications, monographs and reviews is devoted to the study of processes of the refining of indium in different electrolytes [4, 5]. However, the importance of the problem and the complexity of the interpretation of the results require extended set of experimental methods that will provide additional information on related processes and intermediate products of the electrode reactions.

Processes of refining of indium in aqueous solutions with solid electrodes are of practical interest due to environmental safety and the possibility of separation more impurities contained in the rough indium.

\section{Experimental}

Chloride electrolytes were selected to study the electrochemical behavior of indium because of their use in electrochemical technology for obtaining high-purity indium. Indium chloride (reagent grade) was used as indium salt, solution of sodium chloride was chosen as background solution, as indium salts used indium chloride

A platinum electrode was used as working electrode, platinum plate was auxiliary electrode, silver chloride electrode was used as comparing electrode. The working electrode was dipped in the solution of nitric acid (1:1) for removal of impurities from the surface and rinsed thoroughly with distilled water before each measurement.

Electrochemical measurements were carried out on AUTOLAB-30 potentiostat - galvanostat with computer control station. X-ray method and electron microscopy were involved for more detailed study of the processes occurring in the system.

The experiments were performed by varying the temperature, electrolyte components, polarization blending speed, polarization potentials intervals. Current-voltage dependences were taken at least 3 times and processed by graphic and numeri- 
cal methods to evaluate the reproducibility of the measurements.

\section{Results and Discussion}

We used the method of cyclic voltammetry to study the processes occurring in the system, removing the cyclic polarization curves in the different area of the polarization from its own electrode potential $(-0.5,-1.0,-1.3 \mathrm{~V})$ (Fig. 1). This allowed us to see clearly the cathodic waves corresponding to the respective stages of the recovery of indium (III).
Analysis of the cyclic polarization curves (Fig. 1) of indium chloride solution at the platinum electrode showed three waves of by-step recovery of indium traced on the cathodic curve. Similar studies on sulfate and chloride electrolytes were carried out in the papers $/ 6-9 /$.

The first wave is observed at the potential of $0.056 \mathrm{~V}$ and it apparently refers to the process of recovery of $\mathrm{In}^{3+}$ to $\mathrm{In}^{2+}$. This follows from the cyclic polarization curves taken in a narrower range of potentials corresponding to the response observed.

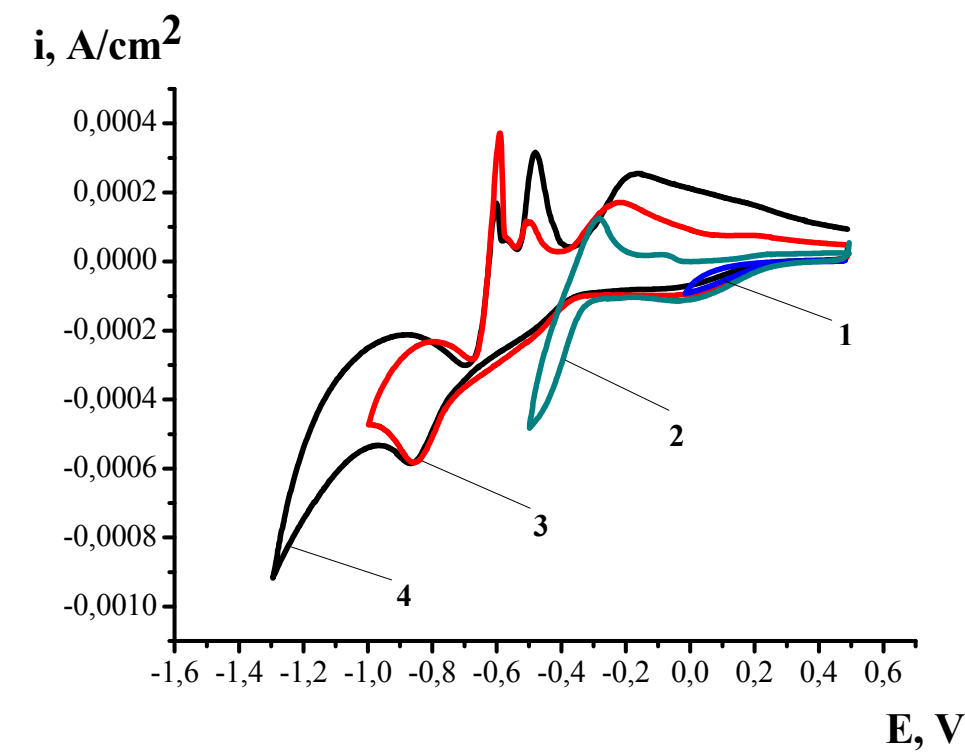

$1-(+0,6-0) \mathrm{B} ; 2-(+0,6-(-0,5)) \mathrm{B} ; 3-(0,6-(-1,0)) \mathrm{B} ; 4-(+0,6-(-1,3)) \mathrm{B}$.

Figure 1 - Cyclic polarization curves on the platinum electrode at different intervals of polarization in solutions of $0.1 \mathrm{M} \mathrm{InCl}_{3}$ at scan rate of $10 \mathrm{mV} / \mathrm{s}$

The second wave of recovery is observed at the potential of $-0.5 \mathrm{~V}$, and linked apparently to the recovery of indium from $\mathrm{In}^{2+}$ to $\mathrm{In}^{+}$. Potential of the third cathodic peak is $-0.85 \mathrm{~V}$ and relates to recovery of indium: $\operatorname{In}^{+} \rightarrow \operatorname{In}^{0}$. Thereafter, the hydrogen evolution $/ 10,11 /$. On the return stroke of the polarization curve cathodic peak is observed at the potential of $-0.67 \mathrm{~V}$ before the peak of oxidation. Its appearance is apparently due to the process of the reduction process indium and hydrogen on already sediment indium:
1) $\mathrm{H}_{2}-2 \mathrm{e} \rightarrow 2 \mathrm{H}^{+}$
2) $\operatorname{In}^{0}-\mathrm{e} \leftrightarrow \operatorname{In}^{+}$

The appearance of the above cathodic peak apparently explained reduction process indium and hydrogen already on precipitated indium

Oxidation of hydrogen leads to alkalization of the solution and the possible sedimentation of indium hydroxide on the surface:

$$
\begin{gathered}
\mathrm{H}_{3} \mathrm{O}^{+}+\mathrm{e}=\mathrm{OH}^{-}+1 / 2 \mathrm{H}_{2} \\
\mathrm{In}^{0}+2 \mathrm{OH}^{-}=\mathrm{In}(\mathrm{OH})_{2}+2 \mathrm{e}
\end{gathered}
$$

Decreasing hydrogen evolution at the return stroke leads to of activation the surface. Availability cathodic peak to the return of the cyclic voltammogram is due to large-current recovery of indium 
and hydrogen on the surface of the electrode coated with indium metal.

Anodic part of the cycle is characterized by 3 oxidation peaks at the following potentials: I $(-0.6 \mathrm{~V})$, II - $(-0,5 \mathrm{~V})$, III - $(-0,22 \mathrm{~V})$. Cyclic polarization curves were obtained at different intervals of polarization. A change in the ratio of currents of oxidation peaks corresponding to the first two stages of the anodic process is observed for different intervals of polarization. The lower region of the polarization, the higher peak current of first step oxidation. Increasing of the polarization interval leads to an increase in current peak of second step oxidation corresponding to the electrode reaction $\mathrm{In}^{+} \rightarrow \mathrm{In}^{2+}$. The observed differences in the ratio of the currents of the first two stages of oxidation are due to incomplete recovery of indium to the metallic state in the case of smaller interval of polarization. Potential of the latter stage of oxidation of indium $\mathrm{In}^{2+} \rightarrow \mathrm{In}^{3+}$ is strongly shifted to negative values in comparison with the corresponding reduction process $\mathrm{In}^{3+}$ $\rightarrow \mathrm{In}^{2+} / 12 /$. This is due to changes in the relative concentrations of the oxidized and reduced forms of indium included in the Nernst equation.

It should be noted that in the entire region of potentials a series of parallel reactions of reduction and oxidation of indium can flow, that can be schematically represented as follows:

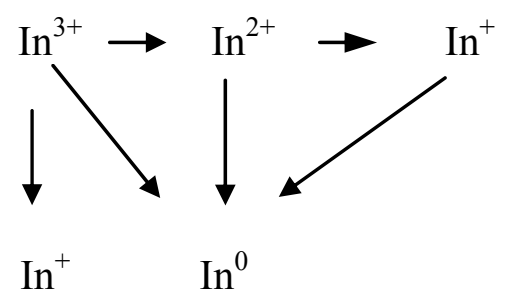

The effect of the potential scan rate $(\mathrm{V})$ on the cyclic voltammograms was studied to determine the nature of the reaction within the range of observed peaks (Fig. 2).

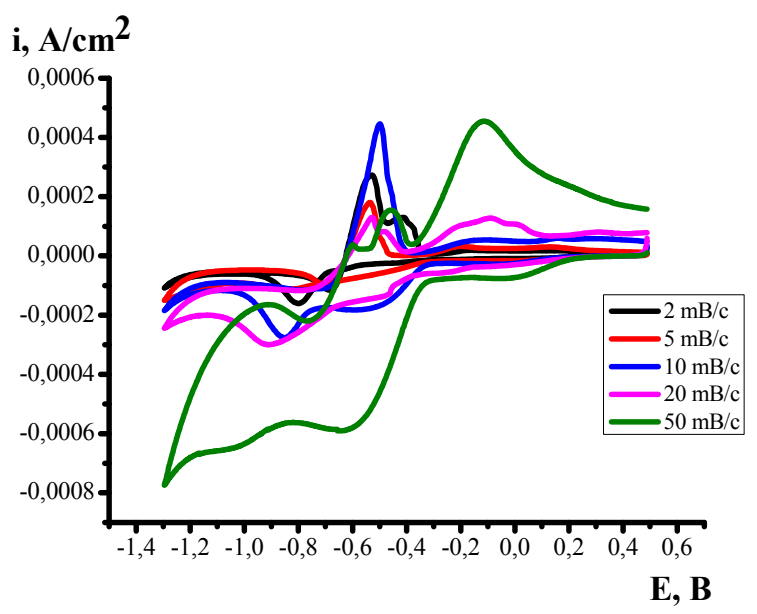

Figure 2 - Cyclic polarization curves on the platinum electrode at different potential scan rates in solutions of $0.1 \mathrm{M} \mathrm{InCl}_{3}$

Analysis of the effect of potential scan rate on the course of cyclic voltammograms showed that current peaks increase with the increase of the speed of scanning and their potential shifted to negative values for cathodic process and to positive values for anodic process.

The values of the potential difference of the peaks of oxidation and reduction at all levels of process of discharge-ionization explain irreversibility of observed electrode reactions.
With increasing concentration of indium ions in solution current peaks of oxidation and reduction of indium in the solution grows (Fig. 3), indicating the growth of rates of these processes. At high concentrations cathodic process retains all regularities that are specific to the concentration of $0.1 \mathrm{~mol} / \mathrm{L}$. Since the increase in the concentration of indium in the solution increases the rate of oxidation stages, there is only one peak of oxidation in the anodic branch corresponding to the last stage of the formation of 
ions of indium (III). Increasing the speed of scan of cyclic voltammograms (Fig. 4) of $0.5 \mathrm{~mol} / \mathrm{L}$ solution of indium chloride practically does not change the currents and potentials of oxidation, due to the

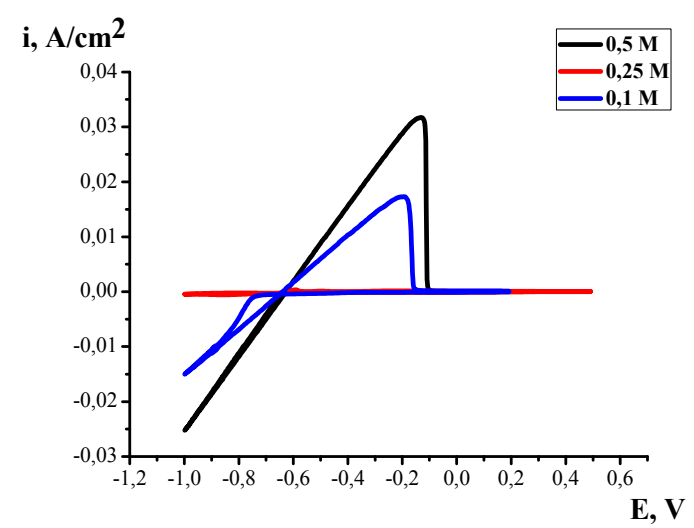

Figure 3 - Cyclic polarization curves on the platinum electrode at different concentrations of $\mathrm{InCl}_{3}$,

In addition to the above factors, we studied the effect of temperature on the processes under study. The increase in temperature leads to the significant increase of the discharge-ionization currents, indicating the growth of rates of these processes (Fig. 5). And oscillations, associated with the mating lack of diffusion and concentration overvoltage. This effect can be achieved, for example, the presence of products in the film surface passivating an electrode.

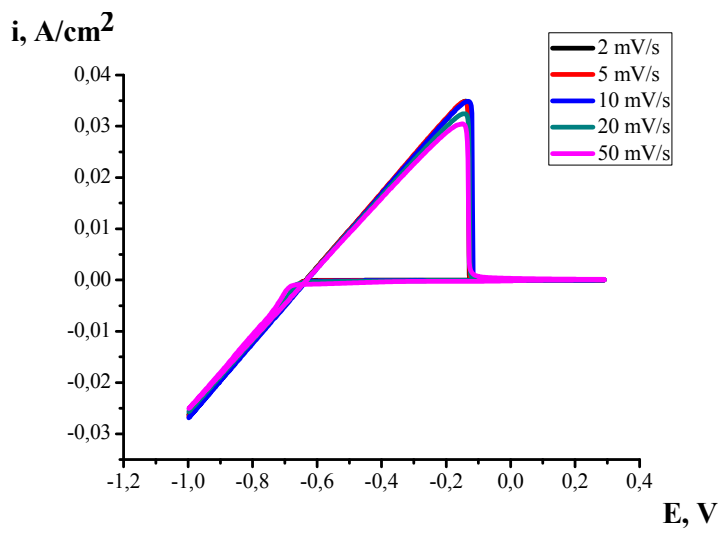

Figure 4 - Cyclic polarization curves on the platinum electrode at different scanning rate, $0.5 \mathrm{~mol} / 1 \mathrm{InCl}_{3}$

process of the discharge of hydrogen, are observed in the cathodic branch at quite high temperatures. Therefore carrying out electrochemical processes above $40^{\circ} \mathrm{C}$ is undesirable and this must be considered when choosing the optimal conditions of indium refining.

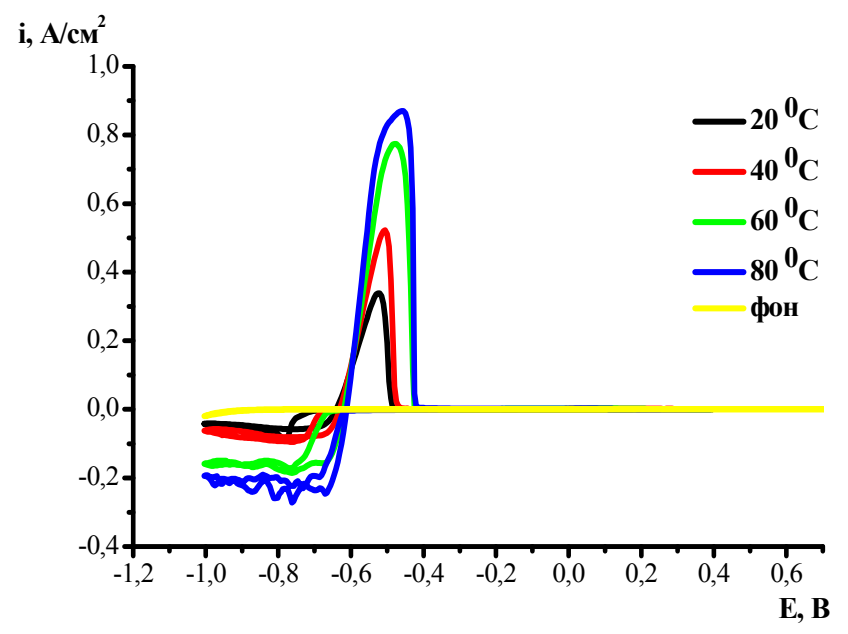

Figure 5 - Cyclic polarization curves on the platinum electrode at different temperatures, $0.1 \mathrm{M} \mathrm{InCl} l_{3}, \mathrm{~V}=10 \mathrm{mV} / \mathrm{s}$

In order to find optimal conditions for sedimentation and dissolution of indium and produce visible precipitates on the surface of platinum, chronoamperograms were obtained at fixed electrolysis potentials (Fig. 6).
Analysis of chronoamperograms at different potentials corresponding to the individual stages of the processes has shown that in the first few seconds there is a sharp increase in current limited by the rate of charge transfer at electrolyte - electrode in- 
terface. Further, we observed a decrease in current to certain limit. In this area the speed of the process is determined by mass transfer.

Carrying out a scanning electron microscopy (SEM + EDX) after electrolysis at different potentials revealed the presence of metallic indium on the surface of platinum electrode at the potential corresponding to the last reduction stage ( $\mathrm{E}=-1.0 \mathrm{~V})$ (Fig. 7). In this case the surface of the electrode is covered by uniform layer of indium with an average size of the resulting granules of about 6.35 microns. Besides on the surface of indium can see film of non-metallic nature likely hydroxide.

Cronoamperograms for sedimentation of indium at the potentials of $-0.85 \mathrm{~V},-1.0 \mathrm{~V},-1.1 \mathrm{~V}$ were obtained. It was found that when the concentration of indium in solution is $0.1 \mathrm{~mol} / \mathrm{L}$ it is preferred to carry out sedimentation at the potential of $-1.0 \mathrm{~V}$, because at the potential of $-0.85 \mathrm{~V}$ sedimentation of indium has just begun and the rate of deposition is not significant, but at the potential of $-1.1 \mathrm{~V}$ hydrogen evolution is observed in addition the process of sedimentation of indium, which affects the quality of sedimented indium.

\section{Conclusions}

1. A stepwise mechanism of the dischargeionization of indium at the platinum electrode from chloride electrolytes was determined.

2. Chronoamperometry methods using X-ray diffraction analysis of the surface found optimal potentials deposition of indium $\left(\mathrm{E}_{\mathrm{red}}=-1.0\right)$

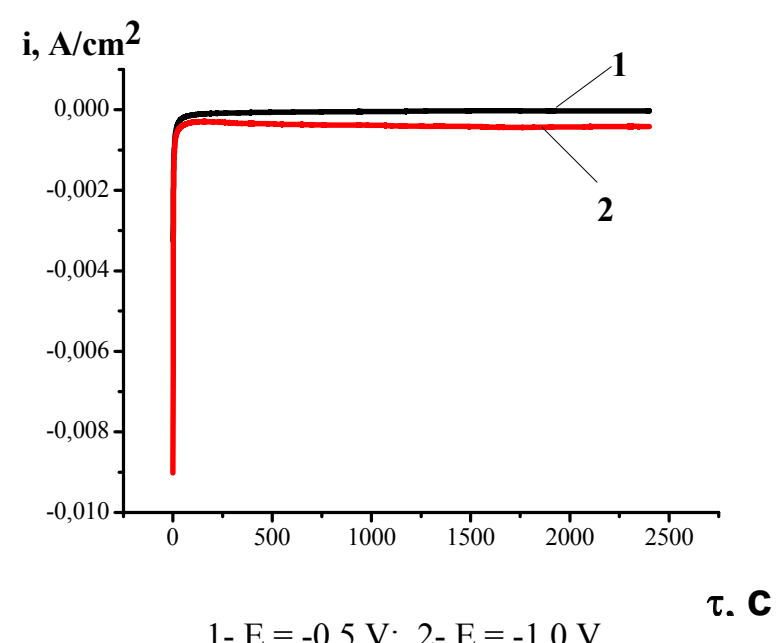

Figure 6 - Chronoamperogram of indium sedimentation on the platinum electrode at, $0.1 \mathrm{M} \mathrm{InCl}_{3}$
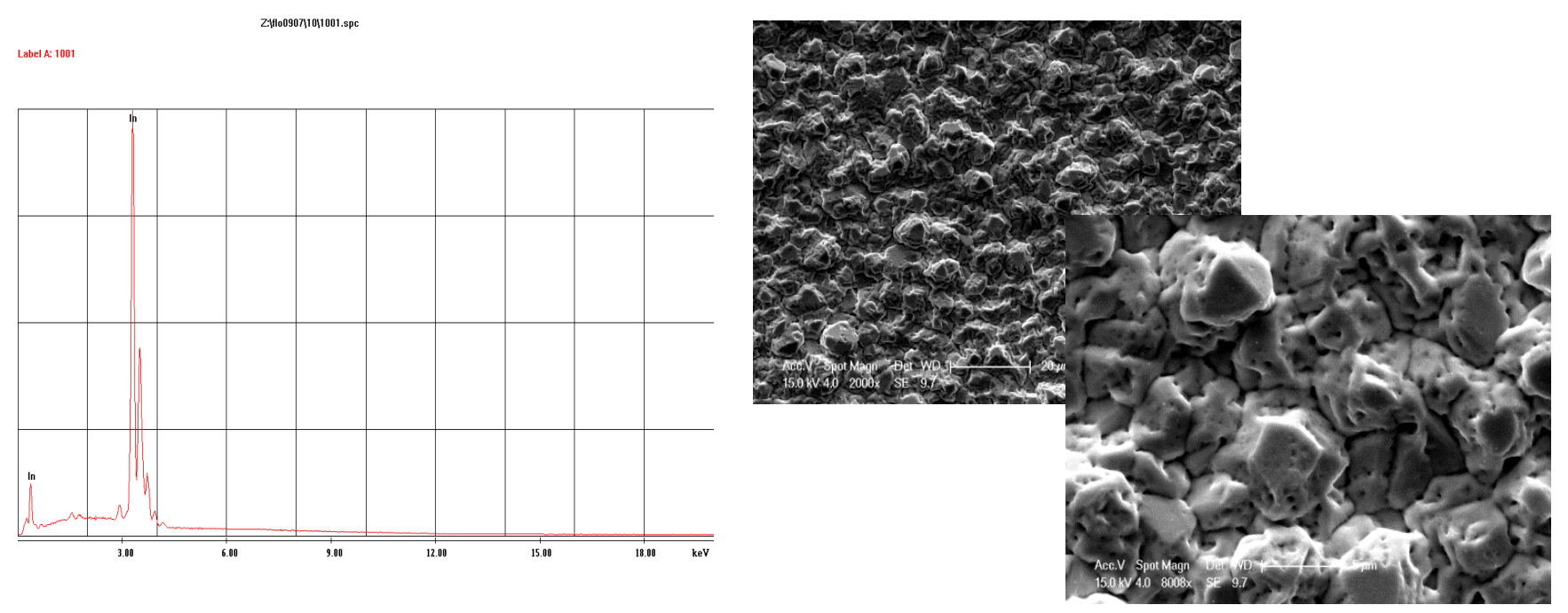

Figure 7 - Results of the analysis of a platinum electrode surface obtained after sedimentation of indium at $\mathrm{E}=-1.0 \mathrm{~V}$ in $0.1 \mathrm{M}$ solution of $\mathrm{InCl}_{3}$. 
3. Increasing the salt concentration of indium in the solution leads to a significant increase in the rates of processes discharge ionization of indium. Optimal concentration is $\mathrm{InCl}_{3} 0.25 \mathrm{M}$.

4. The reaction rate of the discharge-ionization of indium increases with increasing temperature. Optimal is conducting the process at $40{ }^{\circ} \mathrm{C}$.

5. Formation of indium on the surface of the electrode was proved by means of SEM + EDX and $\mathrm{X}$-ray diffraction analysis methods.

\section{References}

1. Alfantazi A.M., Moskalyk R.R. Processing of indium: a review // Minerals Engineering. - 2003. № 16. - pp 687-694.

2. LI Xuan-hai, ZHANG Yan-juan, QIN Quanlun, YANG Jian, WEI Yan-song. Indium recovery from zinc oxide flue dust by oxidative pressure leaching // Trans.Nonferrous Met. Soc. China. 2010. - № 20. - P. 141-145.

3. Hee Nam Kang, Jin-Young Lee, Jong-Young Kim. Recovery of indium from etching waste by solvent extraction and electrolytic refining // Hydrometallurgy. - 2011. - Vol. 110. - P. 120-127

4. ZHOU Zhi-hua, MO Hong-bing, ZENG Dong-ming. Preperation of high purity indium by electrorefining // Trans. Nonferrous Met. Soc. China. - 2004. - Vol. 14. - № 3. - P. 637-640.

5. Kozin L.F., Nagibin S.N., Chabanenko Y.I. Electrochemical refining of indium in aqueous solu- tions with solid electrodes // High-Purity Substances. - 1996. - № 5. - P. 30-45.

6. Marcovac V., Lovrecek B. Studies of the Electrochemical Kinetics of Indium // Electrochemical kinetics of indium. - 1966. - Vol. 113. - № 8. - P. 838-841.

7. Munoz A.G., Bessone J.B. Effects of different anions on the electrochemical behavior of In. // Electrochimica Acta. - 1998. - Vol. 43. - № 9. - P. 1067-1075.

8. Kozin V.F., Omelchuk A.A. Kinetics and mechanism of formation of ions of monovalent indium in the system $\operatorname{In}^{0}-\mathrm{In}_{2}\left(\mathrm{SO}_{4}\right)_{3}-\mathrm{In}_{2} \mathrm{SO}_{4} / /$ Metallurgy of rare and precious metals. - 2006. - № 2. - P. 45-50.

9. Lars Kloo, Jan Rosdahl, Michael J. Taylor. The nature of subvalent gallium and indium in aqueous media // Polyhedron. - 2002. - № 21. - P. 519-524.

10. Munoz A.G., Bessone J.B. Cathodic Behavior of In in aqueous sodium chloride solutions // Electrochimica Acta. - 1998. - Vol. 43. - № 14-15. - P. 2033-2040.

11. Saidman S. B., Bessone J. B. Activation of aluminium by indium ions in chloride solutions // Ekcrrochimica Acta. - 1997. - Vol. 42. - № 3. - P. 413-420.

12. Saidman S. B., Bessone J. B. Anodic behaviour of indium in sodium chloride solutions // Electrochimica Acta. - 1991. - Vol. 36. - № 14. - P. 2063-2067. 